\title{
NÍVEIS SÉRICOS DE TROMBOPOETINA: UM ALERTA PARA ALTERAÇÃO RENAL CAUSADA POR HEPATITE C
}

\author{
SERUM LEVELS OF THROMBOPOIETIN: A WARNING FOR RENAL DAMAGE \\ CAUSED BY HEPATITIS C
}

\author{
Karhen Wiltgen Teixeira, Thaís Ferranti, Raquel Emma Rheinheimer, Eloir Dutra Lourenço
}

Universidade Feevale

\begin{abstract}
Hepatitis $C$ is caused by the hepatitis $C$ virus (HCV) and is considered to be one of the most serious problems in public health because there's no vaccine, passive and cross immunity, or an efficient treatment and may cause death. The virus' detection in the bloodstream depends mainly on the stage at which the disease is and its viremia. Several laboratory tests are performed for the diagnosis to be correct, among them there are immunological, biochemical and molecular methods.Objective: Correlate serum thrombopoietinlevelswith liver damage caused by HCV. Methods: A literature review of the last 16 years from the hematology and biochemistry areas was carried out through the Scielo and PubMed database. Results:Serum thrombopoietin levels may be correlated with liver damage caused by HCV. Conclusion:Correlation between liver damage,serum thrombopoietin levels and infection by $\mathrm{HCV}$ is reported; but more detailed studies are needed.
\end{abstract}

Key words: diagnosis, thrombopoietin, biochemistry
Resumo

A hepatite $C$, causada pelo vírus da hepatite $C$ (VHC), é considerada um dos problemas de saúde pública mais graves no mundo por não haver vacinação, imunização passiva e cruzada, ou tratamento eficaz, podendo levar à morte. A deteç̧ão do vírus na corrente sanguínea depende, principalmente, do estágio no qual a doença se apresenta, e sua viremia. Diversos testes laboratoriais são realizados para que $o$ diagnóstico seja feito de maneira correta, entre eles há métodos imunológicos, bioquímicos e de biologia molecular. Objetivo:Relacionar a dosagem de trombopoetina sérica com dano hepático causado pelo VHC.Métodos:Foi realizada arevisão da literatura das áreashematológica e bioquímica dos últimos 16 anos, atravésdos bancos de dados scielo $e$ PubMed.Resultados:Níveis séricos de trombopoetina podem estar correlacionados com dano hepático causado pelo VHC.Conclusão:Uma correlação entre dano hepático, níveis séricos de trombopoetina e infecção pelo VHC é relatado; porém estudos mais detalhados são necessários.

Palavras chave: diagnóstico, hepatite $C$, trombopoetina, bioquímica 
Introdução

A hepatite $C$ é uma doença hepática causada pelo vírus da hepatite $\mathrm{C}(\mathrm{VHC})$, pertencente à família flaviviridae, de genoma de fita simples (RNA) de polaridade positiva ${ }^{1}$. Simmonds e colaboradores $^{2}$, reuniram em seis grupos e diversos subtipos os diferentes genótipos descobertos pelo sequenciamento do vírus citado acima. Tais genótipos são distribuídos desigualmente no mundo; sendo os genótipos 1 , 2 e 3 os mais frequentes no Brasil ${ }^{3,4}$.

Os indivíduos considerados de risco são aqueles que receberam transfusões de sangue e/ou hemoderivados antes de 1992, usuários de drogas intravenosas, alcoólatras, portadores de HIV, transplantados, hemofílicos, presidiários e sexualmente promíscuos ${ }^{5}$.

Por mais que a frequência de contaminação de profissionais da saúde pelo vírus seja baixa, estão inseridos no grupo de risco ${ }^{6}$.

Ambas a hepatite aguda e crônica, causadas pelo VHC, geralmente são assintomáticas ${ }^{4,7}$. A infecção crônica é caracterizada pela preservação do RNA por mais de seis meses após a infecção. Vale lembrar que ainda não existe vacina contra o vírus, e sequer uma profilaxia eficaz pósexposição ${ }^{5}$.

Quando infectados, os pacientes devem receber uma atenção maior para que haja uma avaliação da possível existência de doença hepática crônica, a qual requer um tratamento antiviral ou outra terapia especializada, como o transplante hepático ${ }^{5}$. Em 1989, surgiram os primeiros testes imunológicos a partir da decodificação genômica do vírus por Choo et al ${ }^{8}$. Essa decodificação se deu por um clone de um paciente infectado pelo vírus da hepatite, então denominado, não $A$ não $B^{8}$.

Em pacientes hepatite $C$ positivos, relata-se uma mortalidade ${ }^{3}$ vezes maior do que pessoas sem a infecção ${ }^{9}$. Os infectados morrem, em média, 22 anos mais jovens do que não infectados, e são mais suscetíveis a desenvolver cirrose e insuficiência hepática e renal ${ }^{10}$.

Este trabalho tem como objetivo correlacionar a diminuição dos níveis séricos de trombopoetina com dano hepático causado pelo VHC, pelo grau de trombocitopenia termostrado ser um marcado útil no prognóstico de pacientes cirróticos, com o achado de trombocitopenia severa $(<50.000 / \mu \mathrm{L})$ em doenças hepática ${ }^{11,12}$. Adicionado a isso, uma diminuição na contagem de plaquetas pode ser um alerta quando se tem a suspeita de cirrose $^{13}$.

\section{Epidemiologia}

Segundo a Organização Mundial de Saúde (OMS)14, cerca de 130-150 milhões de pessoas no mundo não apenas estão infectadas pelo vírus, como também apresentam a forma crônica da doença; sendo que cerca de $80 \%$ desses indivíduos irão evoluir para cirrose hepática ou hepatocarcinoma ${ }^{1,15}$. De caráter infeccioso, apresenta alta taxa de morbidade e mortalidade $^{16}$, ocasionando a morte de aproximadamente 500.000 pessoas, todos os anos,com doenças hepáticas relacionadas com hepatite $C^{14}$. Apesar de ser uma doença mundial, as regiões mais afetadas são África, Ásia Central e Leste Asiático. A distribuição dos 6 genótipos e seus subtipos varia entre as regiões ${ }^{14}$.

Dados divulgados através do Boletim Epidemiológico - Hepatites Virais ${ }^{17}$, os casos notificados por ano no Sistema de Informação de Agravos de Notificação (SINAN) de hepatite C no Brasil, entre os anos de 2004 e 2014, mantiveram-se estáveis, com exceção do ano de 2013 , onde houve um aumento de $49 \%$ quando comparado ao número médio de casos notificados durante esses 10 anos.

Estima-se que há cerca de três milhões de portadores de hepatite C no Brasil, dos quais, grande maioria desconhece ser portador, o que ajuda na disseminação da doença ${ }^{18}$. Segundo Bastos $^{19}$, a hepatite $\mathrm{C}$ evoluiu como uma epidemia chamada silenciosa, apesar da grande magnitude, disseminação mundial e gravidade em termos de saúde pública. Por ser usualmente assintomática na fase aguda, pode persistir por vários anos, aumentando, assim, sua prevalência ${ }^{1}$.

\section{Transmissão}

A transmissão do HCV ocorre de diversas maneiras, como, por exemplo, transfusão de sangue, o que ocasionou a infecção de mais de $90 \%$ dos pacientes até o início dos anos 90, materiais perfuro cortantes contaminadas, e também por via sexual, sendo essa pouco frequente $^{1}$. A probabilidade de infecção por via vertical é de 6\%; já, a amamentação é considerada segura pela maioria dos médicos, pois para que a transmissão do vírus ocorra, a mãe deve ter feridas no mamilo e seu filho cortes na boca ${ }^{20}$. Durante, aproximadamente, 12 meses esses bebês apresentaram anticorpos, o que não significa que estão infectados ${ }^{20}$. 
Clínica

Dos indivíduos infectados, 15-25\% espontaneamente suprimem a viremia, enquanto 75-85\% evoluem para a fase crônica, a qual é confirmada com a presença do material genético do vírus na corrente sanguínea por mais de 6 meses $^{21}$.

Como mencionado anteriormente, a infecção pode apresentar-se assintomática na fase aguda, porém, quando há sinais e sintomas, estes não são específicos de hepatite $C$. Apenas 20-30\% dos pacientes são sintomáticos, reportando sintomas comuns de gripe, dessa maneira não buscando assistência médica ${ }^{21}$. Dos pacientes que apresentam sintomas característicos de hepatite, como icterícia, dor abdominal, anorexia e colúria, apenas 50\% destes procuram ajuda médica ${ }^{21}$.

Para a maioria dos pacientes, a infecção crônica se desenvolve de maneira benigna, sendo a maioria, também, assintomático ${ }^{21}$. Os sintomas mais comuns incluem leves artralgias e mialgias. Elevações moderadas e flutuantes de enzimas hepáticas, como alanina aminotransferase (ALT) e aspartato aminotransferase (AST), ocorrem durante o curso da doença ${ }^{21}$.

Dos pacientes crônicos, apenas 15-20\% evoluem para cirrose hepática ${ }^{22}$; dos quais cerca de $1-4 \%$ evoluem para hepatocarcinoma, e $20 \%$ evoluem para cirrose descompensada ${ }^{21}$.

Em células hematopoiéticas, o VHC interfere na maturação do sangue periférico e, consequentemente, causa trombocitopenia ${ }^{23}$; estando esta condição presente em indivíduos infectados pelo VHC e cirrose hepática ${ }^{24,25}$. Pacientes com fibrose ou cirrose hepática apresentam níveis baixos anormais de trombopoetina (TPO) sérica ${ }^{26}$, já que esta proteína é sintetizada pelo fígado antes de ser liberada na corrente sanguínea ${ }^{26}$. A trombopoetina é o principal regulador da produção de plaquetas, e um feedback entre TPO circulante e a massa das plaquetas foi reportado ${ }^{27}$. No entanto, pouco se sabe sobre a contagem de plaquetas e níveis de TPO em indivíduos aparentemente saudáveis ${ }^{28}$.Contudo, sabe-se que indivíduos com anticorpos positivos para VHC são 2,6 vezes mais propensos a ter uma baixa contagem de plaquetas do que aqueles que têm anticorpos negativos para $\mathrm{VHC}^{29}$.

Trombocitopenia, definida como uma contagem plaquetária $<150.000 / \mu \mathrm{L}$, é a anormalidade mais comum entre pacientes com função hepática comprometida30. Esta alteração ocorre em 64-76\% dos pacientes com cirrose e/ou fibrose, comparados com $6 \%$ de pacientes não-cirróticos com doença hepática crônica ${ }^{31,32}$. A relevância clínica da trombocitopenia é determinada, em parte, por uma contagem baixa de plaquetas e, em parte, por homeostasia anormal ou disfunção plaquetária, as quais impactam o manejo do paciente e o resultado clínico $^{30}$.

A principal causa para o desenvolvimento de trombocitopenia em pacientes infectados por VHC não é totalmente entendido, porém diversas causas são consideradas, como diminuição dos níveis e da atividade de trombopoetina, fibrose hepática, cirrose, hiperesplenismo, supressão da medula óssea pelo vírus, disfunção imune e terapia anti-viral ${ }^{30}$; no entanto, estes não serão discutidos no presente artigo. Variáveis clínicas como idade, gênero, severidade da doença hepática e nível da viremia podem influenciar uma redução severa de plaquetas ${ }^{33}$.

Trombopoetina é a citocina primária responsável pela maturação dos megacariócitos e formação das plaquetas ${ }^{30}$. É uma antiglicoproteína que compartilha sequências homólogas significativas com a eritropoietina ${ }^{30}$. TPO é sintetizada principalmente pelos hepatócitos, e é normalmente liberada, de forma constante, na circulação ${ }^{30}$. TPO circulante se liga a receptores c-Mpl em células-tronco hematopoiéticas, e promove produção de plaquetas de todos os estágios, desde proliferação de megacariócitos até a maturação destes e formação das plaquetas ${ }^{30}$. Durante diversos estágios da megacariocitopoese, TPO circulante interage com outras citocinas hematopoiéticas, como interleucina-11, fator férrico, eritropoietina e célula estromal derivada do fator 130. TPO também se liga a plaquetas, aumentando a ativação destas e suas funções ${ }^{30}$. Por sua vez, as plaquetas internalizam e degradam a antiglicoproteína ${ }^{30}$. Com isso, os níveis séricos de TPO são normalmente regulados pela massa total de plaquetas, incluindo sequestro plaquetário no baço, em vez de pela taxa de produção de $\mathrm{TPO}^{30}$.

Estudos de sinalização de TPO nas células tronco hematopoéticas (HSCs) têm descoberto dois papéis contrastantes para TPO na hematopoese adulta: (1) manter as células tronco em um estado de repouso para preservalas com a idade e (2) expandir as HSCs em tempos de crises, como, por exemplo, após um transplante ${ }^{34}$. Por mais que ambos papéis sejam contrários, a TPO regula o ciclo celular nos dois $\operatorname{casos}^{34}$. O microambiente de HSCs também é 
importante para a regulação entre repouso e proliferação, com as células tronco residindo em um nicho especializado na medula óssea ${ }^{34}$. Interações entre TPO e sinais do nicho podem ser responsáveis por balancear o papel duplo da TPO sobre as células tronco ${ }^{34}$. HSCs de longo prazo estão estreitamente associadas com osteoblastos produtores de TPO no nicho ${ }^{34}$. TPO estimula a expressão do Tie2 nas HSCs, o qual é o receptor de angiopoeina-1, e ajuda a manter as HSCS aderidas ao nicho osteoblástico ${ }^{34}$. Isso sugere que a TPO está ativamente envolvida na manutenção da associação de HSCs com o nicho $^{34}$.

A fim de produzir plaquetas quando necessário, as concentrações de TPO estão vinculadas com o nível plaquetário34. Isso foi notado pela primeira vez quando níveis elevados de TPO foram observados em animais trombocitopênicos ${ }^{34}$. Níveis semelhantemente altos foram observados em resposta a trombocitopenia induzida por quimioterapia ${ }^{34}$. Estudos adicionais mostraram que níveis de TPO são inversamente proporcionais a massa de plaquetas, o que sugere que houve um mecanismo de feedback que detectou a diminuição da massa plaquetária e causou um aumento subsequente de níveis circulantes de $\mathrm{TPO}^{34}$.

TPO é predominantemente produzida pelo fígado, mas também é sintetizado pelo rim, baço e células do estroma na medula óssea ${ }^{34}$. Uma vez que se verificou que os níveis de eritropoietina, a citocina mais diretamente relacionada com a TPO, eram regulados a um nível transcricional em resposta à anemia, era esperado que os níveis de transcrição de TPO fossem regulados por um mecanismo semelhante ${ }^{34}$. Surpreendentemente, verificou-se que o rim e o fígado produzem trombopoetina constitutivamente, com seus níveis de RNAm de TPO não respondentes à trombocitopenia, e que plaquetas eram capazes de absorver TPO a partir de meio condicionado por TPO de uma maneira dose-dependente ${ }^{34}$.

Isso levou a descoberta que TPO é removida da circulação primeiramente por ligação ao $\mathrm{Mpl}^{34}$. As plaquetas e os megacariócitos representam a maior parte dos receptores $\mathrm{Mpl}^{34}$. Em situações como a trombocitopenia, não há plaquetas o suficiente para remover o excesso de TPO da circulação ${ }^{34}$. Os altos níveis de TPO restante resultam na estimulação da produção de megacariócitos e plaquetas ${ }^{34}$. Este mecanismo de controle permite que os níveis de TPO sejam diretamente regulados pela massa plaquetária disponível ${ }^{34}$.
As alterações na TPO produzidas pelas células do estroma na medula óssea parecem ser uma variável adicional na produção total de $\mathrm{TPO}^{34}$. O RNAm de TPO na medula óssea pode aumentar em resposta a trombocitopenia e manipulação experimental ${ }^{34}$. Várias proteínas de grânulos específicos de plaquetas, incluindo fator plaquetário 4, fator de crescimento transformante $\beta$ e trombospondina, podem suprimir a produção de RNAm de TPO em células estromais ${ }^{34}$.

A regulação dos níveis circulantes de TPO parece ser principalmente impulsionada por plaquetas e megacariócitos, uma vez que estas células têm a maioria das $\mathrm{Mpl}$ expressas no corpo. No entanto, TPO também é importante para a manutenção da função de $\mathrm{HSCs}^{34}$.

Pensa-se que a diminuição da produção de plaquetas secundária à infecção pelo HCV seja um fator contribuinte no desenvolvimento de trombocitopenia ${ }^{35}$. Em um estudo com plaquetas reticuladas no sangue periférico como marcador de trombopoiese, pacientes com cirrose hepática tiveram baixa produção de plaquetas ${ }^{35}$. Além disso, a diminuição da carga viral de HCV após o tratamento com interferon alfa correlaciona-se com aumentos significativos na contagem de plaquetas na ausência de hiperesplenismo ou evidência sorológica de auto-anticorpos plaquetários em alguns $\operatorname{casos}^{35}$. Finalmente, dados recentes sobre os ensaios CFU-MK a curto prazo em doentes com hepatite $C$ crônica mostraram uma depressão evidente no número de unidades formadoras de colóniasmegacariócitos ${ }^{35}$. A totalidade destes dados sugerem que o VHC pode afetar diretamente a megacariopoiese ${ }^{35}$.

Em um estudo realizado por Afifi et $\mathrm{al}^{29}$, os níveis séricos de TPO nos grupos I (pacientes VHC positivo com trombocitopenia) e II (pacientes VHC positivos sem trombocitopenia) não mostraram diferença estatística significativa quando comparados com o grupo controle. Estes resultados são consistentes com outros previamente relatados, os quais encontraram que os pacientes trombocitopênicos com infecção viral crônica por hepatite C apresentavam níveis séricos de TPO semelhantes aos do grupo controle saudável ${ }^{29}$.

Por outro lado, Afifi et $\mathrm{al}^{29}$. também constataram que em pacientes com VHC e trombocitopenia leve, o nível sérico médio de TPO foi significativamente elevado quando comparado com o grupo controle ${ }^{29}$. Este achado também foi apoiado por um estudo anterior que relatou que os níveis séricos de TPO foram 
elevados em pacientes com estágio inicial de hepatite viral crônica ${ }^{29}$. À medida que a doença progride de fibrose leve para cirrose, a diminuição da produção de TPO pode contribuir para o desenvolvimento da trombocitopenia na cirrose $^{29}$.

Numa tentativa de explicar as conclusões acima, os autores sugeriram que a produção de TPO é mantida em certos níveis até que se desenvolva um comprometimento profundo da função hepática ${ }^{29}$. No entanto, a produção de TPO por outros órgãos compensa a diminuição da produção de TPO pelo fígado ${ }^{29}$. E concluíram que os níveis séricos de TPO em pacientes com infecção viral por hepatite $\mathrm{C}$ e trombocitopenia não diferiram significativamente daqueles de indivíduos saudáveis, excluindo um defeito na produção de TPO nos estágios iniciais da doença $^{29}$.

No entanto, em pacientes com cirrose hepática extensa e/ou fibrose e subsequente redução da função dos hepatócitos, a produção de TPO pode ser reduzida ${ }^{29}$. Uma correlação entre níveis séricos baixos de TPO e diminuição global da função hepática tem sido relatado ${ }^{30}$.

\section{Diagnóstico}

O diagnóstico de hepatite $\mathrm{C}$ pode ser realizado através de exames de biologia molecular, imunológicos ou bioquímicos. Um dos exames moleculares, se baseia na reação quantitativa em cadeia de polimerase (PCR) na procura do RNA do vírus da hepatite $C^{36}$; no entanto, testes moleculares não serão discutidos no decorrer desta revisão. Esse exame tem como finalidade medir a quantidade de vírus presente na corrente sanguínea do paciente para avaliar a carga viral inicial, redução ou não da mesma durante a terapia e uma estabilidade da resposta virológica, definida como uma quantidade não detectável de VHC por PCR seis meses após o término da terapia ${ }^{36}$. No entanto, níveis de RNA do VHC não equivalem à lesão hepática, duração da infecção ou gravidade da doença ${ }^{36}$.

Os testes imunológicos (ou imunoensaios) baseiam-se na detecção de anticorpos anti-VHC no plasma do indivíduo infectado ${ }^{16}$. Podem ser divididos em testes de triagem ou confirmatórios $^{16}$. Os primeiros são imunoensaios que detectam anticorpos anti-VHC sem que haja a distinção dos antígenos; podendo ser subdivididos em teste enzimático colorimétrico ou quimioluminescente ${ }^{16}$. Já, os testes confirmatórios, diferenciam os anticorpos presentes no soro e/ou plasma do indivíduo ${ }^{16}$.
Os testes bioquímicos são solicitados para diagnóstico e avaliação de pacientes com suspeita de hepatite viral, nos quais são dosadas enzimas hepáticas, como alanina aminotransferase (ALT) e aspartato aminotransferase $(\mathrm{AST})^{16}$. Normalmente, essas enzimas se apresentam aumentadas na circulação sanguínea quando há lesão hepatocelular ${ }^{16}$; o que foi demonstrado em um estudo realizado por Puoti ${ }^{37}$ em doadores de sangue, anti-VHC positivos, onde os níveis de ALT estavam aumentados em até duas vezes o valor do limite superior em $30 \%$ dos indivíduos, entre uma e duas vezes em $40 \%$ e normais em $30 \%$ dos casos.

Segundo Wang et $\mathrm{al}^{25}$, níveis de trombopoetina e contagem de plaquetas estão altamente correlacionados com dano da função hepática e severidade da fibrose hepática em pacientes infectados com VHC cronicamente. Concluíram, também, que infecção por HCV é altamente associada com trombocitopenia a qual está fortemente associada à dano hepatocelular e fibrose hepática. No entanto, trombocitopenia é uma anormalidade laboratorial que não pode ser considerada como um sintoma específico para diagnóstico ${ }^{24}$, mesmo sendo a anormalidade hematopoiética mais comum em pacientes com cirrose hepática crônica ${ }^{38}$.

\section{Tratamento}

O tratamento antiviral é recomendado para pacientes crônicos que apresentam altos riscos de progredir para cirrose ${ }^{37}$. Esses pacientes devem apresentar RNA do VHC detectáveis, níveis, muitas vezes, elevados de transaminase, e seus resultados de biópsia hepática devem indicar, pelo menos, fibrose portal ou em ponte ou, então, níveis moderados de inflamação e necrose ${ }^{37}$.

Porém, não é indicado para todos os pacientes crônicos, como os que apresentam um dano hepático mais avançado ${ }^{37}$. Pacientes com cirrose descompensada não são tratados com uma terapia a base de interferon devido ao risco de exacerbação da doença. Todavia esses pacientes estão mais susceptíveis a serem identificados sem prévio rastreio ${ }^{37}$. Apesar de haver a possibilidade de pacientes com cirrose compensada serem tratados, a resposta destes ao tratamento será mais baixa do que aqueles sem cirrose $^{37}$. Geralmente pacientes com abuso ativo de álcool ou droga ilícita não são tratados até que esse comportamento tenha sido descontinuado a seis meses ou mais, embora 
haja recomendações de que o tratamento para cirrose seja oferecido em conjunto com uma terapia de abuso de substâncias ${ }^{37}$. Além disso, o tratamento também não é recomendado para pacientes com graves problemas médicos ou comorbidades psicológicas, devido aos sérios efeitos colaterais das terapias atuais ${ }^{37}$.

Transfusões repetitivas de plaquetas não são uma solução prática para trombocitopenia porque as plaquetas apresentarem uma meiavida curta e por causa da aloimunização associada que pode ocorrer ${ }^{39}$. O risco de complicações associadas a transfusão também aumento significativamente com esse tratamento.

O manejo de trombocitopenia em pacientes cirróticos tem sido um desafio por muitos anos39. Desvios renais foram desenvolvidos na década de 1960, porém foram abandonados por uma alta mortalidade por falência renal ${ }^{39}$. Esplenectomia e, posteriormente, esplenectomia parcial (PS), ganharam popularidade por conta do menor número de complicações associadas com o procedimento ${ }^{39}$. Com técnicas de laparoscopia refinadas, esplenectomias têm sido realizadas desde o final da década de 1990 com complicações mínimas e uma melhor resolução da trombocitopenia em comparação com $\mathrm{PS}^{39}$. Embolização esplênica tem sido realizada com sucesso desde a década de 197039. Hoje em dia, embolização esplênica parcial tem ganhado popularidade $^{39}$. Novas técnicas, como ablação porradiofrequência e estimuladores de TPO, estão sendo investigados para o tratamento de trombopoetina associada a doenças hepáticas ${ }^{39}$.

Por mais que agonistas de TPO e agentes alvos sejam instrumentos alternativos não invasivos para o tratamento de trombocitopenia devido a cirrose hepática, suas capacidades de melhorar a primeira condição, ainda estão sobre investigação em ensaios clínicos ${ }^{39}$.

\section{Metodologia}

Foram revisados artigos científicos provenientes das bases de dados PubMed e Scielo, utilizando as palavras chaves: "hepatite C", "HCV", "métodos bioquímicos", "diagnóstico" e "trombopoetina", em diversas combinações nas línguas portuguesa e inglesa, com a última sempre presente na caixa de busca. Foram encontrados 40 artigos, dos quais 30 foram selecionados por descreverem a infecção causada pelo $\mathrm{HCV}$, o ciclo biológico da trombopoetina ou correlacionar os níveis de trombopoetina sérica com dano hepático causado ou não pelo HCV; e por terem sido publicados entre os anos de 2000 e 2016.

\section{Resultados e Discussões}

O RNA do VHC pode ser detectável no soro do paciente dentro de 1-3 semanas após a infecção; com isso, anticorpos anti-VHC já podem ser detectados após 3 semanas ${ }^{40}$. Por outro lado, as transaminases apenas sofreram uma elevação após decorrido, no mínimo, 1 mês desde a exposição, resultado de uma lesão hepática ${ }^{40}$.

Como mencionado previamente, níveis de trombopoetina e contagem de plaquetas são altamente correlacionados com dano da função hepática e severidade da fibrose hepática em pacientes infectados com VHC cronicamente ${ }^{25}$; estando a trombocitopenia altamente associada à dano hepatocelular e fibrose hepática causado pelo VHC. No entanto, por ser uma anormalidade inespecífica, não pode ser considerado isoladamente como diagnóstico para infecção pelo $\mathrm{VHC}^{24}$.

De acordo com um estudo realizado por Kauf et $\mathrm{al}^{24}$, quando comparados com pacientes normais, os indivíduos infectados com níveis de plaquetas baixos tendem a ser mais velhos (55.3 vs 46 anos) e apresentam níveis mais altos de ALT (81.5 vs 50).

No estudo realizado por $\mathrm{Tsai}^{28}$, foi encontrado uma diferença significativa nos índices plaquetários entre o grupo infectado pelo VHC e o grupo controle negativo. Quando comparado com o grupo controle, os pacientes infectados apresentaram uma baixa significativa na contagem de plaquetas e seus volumes (PCT), mas um aumento significativo do tamanho das plaquetas (PDW), volume médio (MPV), e na proporção de células plaquetárias grandes ( $P$ LCR). Com isso, pode-se dizer que o grupo infectado pelo $\mathrm{VHC}$ apresentou plaquetas mais largas, mais irregulares e em quantidade aumentada quando comparado com o grupo controle ${ }^{28}$

Quando realizaram a análise dos efeitos comparativos para a carga viral doVHC, encontraram que as plaquetas têm uma correlação negativa significativa com a carga viral; já a carga viral tem uma correlação positiva significativa com trombopoetina ${ }^{28}$. Ou seja, foi constatado que pacientes com uma carga viral aumentada apresentavam uma diminuição do nível de plaquetas, enquanto que os que apresen ${ }^{24}$ taram baixos níveis de plaquetas tinham trombopoetina aumentada ${ }^{28}$. 
Por mais que níveis séricos baixos de TPO estejam associados com cirrose hepática, em alguns estudos foram encontrados níveis normais e até mesmo aumentados de TPO sérico em pacientes cirróticos ${ }^{38}$.

\section{Conclusões}

Em pacientes com infecção pelo VHC não tratada, trombocitopenia é usualmente leve a moderada, e piora com a progressão da doença, conforme os pacientes desenvolvem fibrose extensiva e/ou cirrose ${ }^{30}$.

As principais causas de trombocitopenia em doenças hepáticas induzidas pelo VHC incluem sequestro como um resultado de hiperesplenismo secundário à hipertensão portal e esplenomegalia, supressão da medula óssea ou pelo VHC diretamente ou pelo uso de interferon no tratamento do vírus, destruição plaquetária mediada pelo sistema imune envolvendo anticorpos anti-plaquetas e/ou associada ao complexo imune de depuração de plaquetas, e produção prejudicada de TPO por dano hepático ${ }^{30}$.

A descoberta de que a trombopoetina age como uma citocina que regula a maturação e a produção de megacariócitos e plaquetas tem modificado o conceito de trombocitopenia em pacientes com doença hepática crônica ${ }^{41}$. A fibrose hepática também pode ter um papel determinante na baixa produção de TPO entre os pacientes com hepatite crônica por ser uma patologia que inicia o processo de hipertensão portal e a diminuição da função hepática ${ }^{41}$.

Apesar de existirem evidências de que níveis baixos de trombopoetina estejam relacionados com a perda de função hepática devido à infecção pelo VHC, há também estudos que mostram o contrário. Com isso, pode-se concluir que investigações mais detalhadas são necessárias para um melhor entendimento da correlação entre trombopoetina e perda da função hepática devido ao vírus da hepatite $\mathrm{C}$.

\section{Referências}

1. Strauss E. Hepatite C. Rev Soc Bras Med Trop 2001 Jan-Fev;34(1):69-82.

2. Simmonds $P$, Alberti $A$, Alter $\mathrm{HJ}$, Bonino F, Bradley DW, Brechot C, et al. A proposed system for the nomenclature of hepatitis $C$ virus genomes. Hepatology 1994;19:1321-1324.

3. Martins T, Narciso-Schiavon JL, Schiavon LL. Epidemiologia da infecção pelo vírus da hepatite C. Rev Assoc Med Bras 2011;57(1):107112.

4. Alvariz FG. Hepatite C Crônica: aspectos clínicos e evolutivos. Moderna Hepatologia 2004;30:20-32.

5. Ferreira CT, da Silveira TR. Hepatites virais: aspectos da epidemiologia e da prevenção. Rev Bras Epidemiol 2004;7(4):473-487.

6. Figueiredo EQG, Cotrim HP, TavaresNeto J. Frequência do Vírus da Hepatite C em profissionais da saúde: revisão sistemática da literatura. GED 2003;22(2):53-60.

7. Centers for Disease Control and Prevention. Guidelines for Viral Hepatitis Surveillance andCase Management. Atlanta, GA; 2005.

8. Brandão $A B M$, Fuchs $S C$, Silva MAA, Emer LF. Diagnóstico da hepatite $C$ na prática médica. Pan Am J Public Health 2001;9(3):161168.

9. Mooorman AC, Gordon SC, Rupp LB, Spradling PR, Teshale EH, Lu M, et al. Baseline characteristics and mortality among people in care for chronic viral hepatitis: the chronic hepatitis cohort study. Clin Infect Dis 2013;56(1):40-50.

10. Ly KN, Xing J, Klevens RM, Jiles RB, Holmberg SD. Causes of death and characteristics of decedents with viral hepatitis, United States, 2010. Clin Infect Dis 2014;58(1):40-49.

11. Afdhal N, McHutchison J, Brown R, Jacobson I, Manns M, Poordad F, et al. Thrombocytopenia associated with chronic liver disease. J Hepatol 2008;48:1000-1007.

12. Peck-Radosavljevic M. Thrombocytopenia in liver disease. Can J Gastroenterol 2000;14 Suppl D: 60D-66D.

13. Hayashi $\mathrm{H}$ et al. Management of thrombocytopenia due to liver cirrhosis. World J Gastroenterol 2014 March 14;20(10):2595-2605.

14. World Health Organization [http://www.who.int]. Hepatitis C [acesso em23 abr 2016]. Disponível em: http://www.who.int/mediacentre/factsheets/fs1 64/en/.

15. Sy T, Jamal MM. Epidemiology of Hepatitis C Virus (HCV) Infection. Int J Med Sci 2006;3:41-46.

16. Buriol, ACS. Análise de Marcadores laboratoriais utilizados no diagnóstico do vírus da hepatite $\mathrm{C}(\mathrm{HCV})$ em pacientes hemodialisados de Porto Alegre - RS. Canoas. Dissertação [Mestrado em Diagnóstico Genético e Molecular] - Universidade Luterana do Brasil; 2007. 
17. Ministério da Saúde. Boletim Epidemiológico - Hepatites Virais Ano IV no 01. [monografia na Internet]. Brasil: 2015; [acesso em 24 abr 2016]. Disponível em: http://www.aids.gov.br/sites/default/files/anexo s/publicacao/2015/58210/_p_boletim_hepatites _final_web_pdf_p_16377.pdf.

18. Brasil. Ministério da Saúde. Secretaria de Vigilância em Saúde. Departamento de Vigilância Epidemiológica.Hepatites virais: o Brasil está atento / Ministério da Saúde, Secretaria de Vigilância em Saúde, Departamentode Vigilância Epidemiológica 3 ed. Brasília 2008; [acesso em 25 abr 2016]. Disponível em: http://bvsms.saude.gov.br/bvs/publicacoes/hepa tites_virais_brasil_atento_3ed.pdf.

19. Bastos FI. O Som do Silêncio da Hepatite C [monografia na Internet].Rio de Janeiro: Editora FIOCRUZ;2007 [acesso em 25 abr 2016]. Disponível em: http://static.scielo.org/scielobooks/ryvp9/pdf/ba stos-9788575413715.pdf.

20. Instituto de Tecnologia em Imunobiológicos (Bio-Manguinhos) [http://www.bio.fiocruz.br/]. Hepatite C: sintomas, transmissão e prevenção[acesso em 30 abr 2017].Disponível em: http://www.bio.fiocruz.br/index.php/hepatite-csintomas-transmissao-e-prevencao.

21. Lee J, Conniff J, Kraus C, Schrager S. A Brief Clinical Update on Hepatitis C - The Essentials. WMJ 2015 Dec;114(6):263-269.

22. Trevizoli JE. Hepatite $\mathrm{C}$ em pacientes portadores e insuficiência renal crônica em hemodiálise: aspectos histológicos, bioquímicos e virológicos. Brasília. Tese [Doutorado em Patologia Molecular] - Faculdade de Medicina da Universidade de Brasília; 2008.

23. El Barbary MA, Saad AEM, Attia FM, Mandour MI, Haidara MA, Dallak MM, et al. Thrombocytopenia In Patients With Chronic Hepatitis C: A Possible Role of HCV on Platelet Progenitor Cell Maturation. Angiology 2009 Aug;61(3):304-313.

24. Kauf TL, Nelson DR, Schelfhout J, Delaney JA, Wang PF. Trends in the prevalence of thrombocytopenia among individuals infected with hepatitis C Virus in the United States, 19992008. BMC Research Notes. 2012;5:142.

25. Wang CS, Yao WJ, Wang ST, Chang TT, Chou P. Strong association of hepatitis $C$ virus (HCV) infection and thrombocytopenia: implications from a survey of a community with hyper endemic HCV infection. Clin Infect Dis 2004 Sep;39(6):790-796.
26. Giannini E, Botta F, Borro P, Malfatti F, Fumagalli $A$, Testa $E$, et al. Relationship between thrombopoietin serumlevels and liver function in patients with chronic liver disease related to hepatitis C virus infection. Am J Gastroenterol. 2003 Nov;98(11):2516-2520.

27. Hobisch-Hagen $P$, Jelkmann W, Mayr A, Wiedermann FJ, Fries D, Herold $M$, et al. Low platelet count and elevated serum thrombopoietin after severe trauma. Eur J Haematol. 2000 Mar;64(3):157-163.

28. Mei-Hua T, Kuei-Hsiang L, Kuan-Tsou L, Chi-Ming $\mathrm{H}$, Hung-Shiang $\mathrm{C}, \mathrm{Yu}$-Chang $\mathrm{T}$, et al. Predictors for Early Identification of Hepatitis C Virus Infection.BioMed Research International2015;2015:7 pages.

29. Afifi OA, Sewify EM, El-Attar MM, Taie AO, Mostafa AK. Hepatitis C Virus-Associated Thrombocytopenia is Not Related to Serum Thrombopoietin Levels. Saudi J Gastroenterol. 2007 Apr-Jun;13(2):76-80.

30. Weksler BB. Review article: The pathophysiology of thrombocytopenia in hepatitis $C$ virus infection and chronic liver disease. Aliment Pharmacol Ther 2007 Nov;26 Suppl 1:13-19.

31. Giannini EG. Review article: Thrombocytopenia in chronic liver disease and pharmacologic treatment options. Aliment Pharmacol Ther 2006; 23: 1055-1065;

32. Bashour FN, Teran JC, Mullen KD. Prevalence of peripheral blood cytopenias (hypersplenism) in patients with nonalcoholic chronic liver disease. Am J Gastroenterol 2000;95:2936-2939;

33. Olariu M, Olariu C, Olteanu D. Thrombocytopenia in Chronic Hepatitis C. J Gastrointestin Liver Dis Dec 2010;19(4):381-385.

34. Graaf De, Carolyn A, Metcalf D. Thrombopoietin and Hematopoietic Stem Cells. Cell Cycle 2011 May;10(10):1582-1589.

35. Stasi R, Chia LW, Kalkur P, Lowe R, Shannon MS. Pathobiology and Treatment of Hepatitis Virus-Related Thrombocytopenia. Mediterr J Hematol Infect Dis. 2009;1(3): e2009023.

36. Wilkins T, Malcolm JK, Raina D, Schade RR. Hepatitis C: Diagnosis and Treatment. Am Fam Physician 2010 Jun;81(11):1351-1357.

37. Chou R, Clark E, Helfand M. Screening for Hepatitis C Virus Infection [Internet]. Rockville (MD): Agency for Healthcare Research and Quality (US); 2004 Mar.(Systematic Evidence Reviews, No. 24) [acesso em 28 set 2016]. 
Disponível

em: http://www.ncbi.nlm.nih.gov/books/NBK43249/.

38. Temel T, Cansu DU, Temel HE, Ozakyol AH. Serum Thrombopoietin Levels and Its Relationship with Thrombocytopenia in Patients with Cirrhosis. Hepat Mon. 2014 May; 14(5): e18556.

39. Gangireddy VGR, Kanneganti PC, Sridhar $\mathrm{S}$, Talla $\mathrm{S}$, Coleman T. Management of thrombocytopenia in advanced liver disease. Can J Gastroenterol Hepatol 2014;28(10):558-564.

40. Vaz AJ, Takei K, Bueno EC. Imunoensaios: fundamentos e aplicações. Rio de Janeiro: Guanabara Koogan; 2012.

41. Thofehrn VV, Munhoz TP.Trombocitopenia: Uma manifestação extrahepática da infecção pelo vírus da hepatite C.PUCRS. [acesso em 30 set 2016]. Disponível em:

http://www.laboratoriodrthofehrn.com.br/trabal hos.php.

\section{Endereço para Correspondência}

Universidade Feevale

$e$-mail

thaisferranti@yahoo.com.br

Recebido em 04/12/2016

Aprovado em 25/05/2017

Publicado em 26/07/2017 